\title{
Urgences
}

\section{Repartir en quatrième !}

\section{Jean Cossette}

Numéro 4, 2e trimestre 1982

URI : https://id.erudit.org/iderudit/025053ar

DOI : https://doi.org/10.7202/025053ar

Aller au sommaire du numéro

Éditeur(s)

Urgences

ISSN

0226-9554 (imprimé)

1927-3924 (numérique)

Découvrir la revue

Citer ce document

Cossette, J. (1982). Repartir en quatrième ! Urgences, (4), 5-6.

https://doi.org/10.7202/025053ar

Ce document est protégé par la loi sur le droit d'auteur. L'utilisation des services d'Érudit (y compris la reproduction) est assujettie à sa politique d'utilisation que vous pouvez consulter en ligne.

https://apropos.erudit.org/fr/usagers/politique-dutilisation/
Cet article est diffusé et préservé par Érudit.

Érudit est un consortium interuniversitaire sans but lucratif composé de l'Université de Montréal, l'Université Laval et l'Université du Québec à Montréal. Il a pour mission la promotion et la valorisation de la recherche. https://www.erudit.org/fr/ 


\section{REPARTIR EN QUATRIĖME!}

Malgré l'augmentation continue du prix du pétrole, nous avons décidé à URGENCES de repartir en quatrième! De toute façon nous n'avions pas le choix puisque la littérature constitue l'essence même de notre existence. Puis, avouons-le, nous sommes optimistes... II suffit d'ailleurs de regarder du coin de l'oeil dans le rétroviseur pour s'apercevoir que nos principaux objectifs ont été atteints, en particulier celui de doter le Regroupement des Auteurs de l'Est du Québec d'un véhicule littéraire à dimensions professionnelles, sans oublier l'accès aux auteurs non-membres, et celui d'offrir, à vous lecteurs, un moyen de transport sûr et rapide pour vous évader de vos quotidiens en mal de voyages. Dans ce dernier cas, vous n'avez qu'à lire le manuel d'instruction numéro par numéro et renouveler votre abonnement pour ne pas tomber en panne des sens. Avec les trois premiers numéros, 34 auteurs habitant la région Bas St-Laurent-Gaspésie ont emprunté les avenues d'URGENCES pour se rendre chez-vous question d'y livrer leur message. Ce quatrième numéro ajoute 8 autres passagers, soit un total de 42 auteurs dont les textes ont fait leur chemin dans les limites fixées par notre Comité de lecture. D'un autre côté, les arrivées de textes pour les numéros ultérieurs ne cessant de croître en qualité et en nombre, les augures nous semblent favorables. Allons! Trève de bavardages! Fêtons le départ de notre deuxième année et sablons le champagne avec notre équipage puisque...

...Huguette Légaré, dans ses "Études de cadences", nous fait déjà respirer le vent du large à pleins poumons et nous transporte à fleur de peau de la nature ensorcelée et ensorcelante. Déjà ce beau vestibule franchi que nous nous retrouvons derrière les grandes portes d'un "Couvent de ville" où Jean Deschamps nous invite à regarder par les judas. Celui-ci aura tôt fait de nous mettre au parfum sur le langage de la gent espiègle qui sillonne les récréations, sorte de jungle fourmillante où la répartie palpite. Puis ce temps d'arrêt, cette pause, ce souffle léger sur les images diaphanes de "La lunaction" de Bernard Boucher, avant d'enchaîner avec un extrait des "Réconciliations" de Line Arsenault, cette quête intimiste dans l'imagerie quotidienne comme un bilan dans la mouvance du temps. Sous ces "Lanternes vacillantes" que je vous offre, j'ai "couché sur les trottoirs les phrases, les pas 
et les silences de mes forêts intérieures", pour qu'elles puissent s'allumer, ne serait-ce qu'un instant fugitif, à votre fenêtre.

Au sortir de la nuit, un pas dans "L'écriture" telle que la conçoit Micheline Morrisset avec les mots pour le dire et le verbe en gibecière. De son côté, Jean-Yves Dupuis nous apprend que dans la "pantomime" il n'y a bien souvent qu'une question de ridicule. Son héroïne en fera malheureusement les frais. Un texte qui ne peut laisser indifférent. Toujours dans la veine éreintante de nos malheurs humains, dans le brouhaha de ce qui nous colle à la peau, "Le funambule" de Ghislain Bérubé viendra jouer sur l'équilibre précaire des jours. Après son numéro, "Mimes et jardins" de Mario Joubert où nous pourrons trouver courage et lucidité dans une façon particulière de dire. Une fois sortis de sous le grand chapiteau, nous entrerons dans le temple sacré du fonctionnarisme pour découvrir que cette maladie, parfois incurable, peut devenir fonctionnelle pour les besoins de la littérature; Marielle Sénéchal nous le démontrera de belle façon dans "Grandeur de rêve...". Puis, Denuis Saint-Yves viendra nous léguer quelques fragments tirés de "la vie précise"; peut-être pourrez-vous dire aussi, après les avoir parcourus: "il a suffi de si peu que nous nous sommes brûlés à l'évidence". Pour terminer notre quatrième traversée en solidaires, le vent dans la plume de Gilbert Dupuis fera naître une "Tempête d'amours dans un verre d'eau-de-vie". Vous pourrez vous y laisser couler à Bic ou ailleurs, peu importe puisque l'auteur fournit également la bouée. Ėtant donné qu'il s'agit d'une première à URGENCES, soulignons les apports graphiques de Myriam Ol'Sommer et de Pauline Veilleux. Nul doute que ces parenthèses picturales contribueront à agrémenter votre séjour en ce quatrième numéro.

Bref, à URGENCES, l'équipe se sent le vent en poupe. Ce qui ne veut pas dire qu'elle peut naviguer seule. Votre aide et votre encouragement (j'allais dire abonnement) nous sont encore aussi salutaires qu'au premier numéro car en définitive, URGENCES signifie une sorte de S.O.S. permanent.

Jean Cossette pour le Comité de direction 